\title{
The comparative immunotoxicity of mesoporous silica nanoparticles and colloidal silica nanoparticles in mice
}

This article was published in the following Dove Press journal:

International Journal of Nanomedicine

4 January 2013

Number of times this article has been viewed

\author{
Soyoung Lee ${ }^{1, *}$ \\ Mi-Sun Kim ${ }^{1, *}$ \\ Dakeun Lee ${ }^{2}$ \\ Taeg Kyu Kwon ${ }^{3}$ \\ Dongwoo Khang ${ }^{4}$ \\ Hui-Suk Yun ${ }^{5}$ \\ Sang-Hyun Kim' \\ 'CMRI, Laboratory of \\ Immunotoxicology, Department of \\ Pharmacology,School of Medicine, \\ Kyungpook National University, \\ Daegu, Republic of Korea; \\ ${ }^{2}$ Department of Pathology, School \\ of Medicine, Kyungpook National \\ University, Daegu, Republic of Korea; \\ ${ }^{3}$ Department of Immunology, School \\ of Medicine, Keimyung University, \\ Daegu, Republic of Korea; ${ }^{4}$ School of \\ Nano and Advanced Materials Science \\ and Engineering, Gyeongsang National \\ University, Jinju, Republic of Korea; \\ ${ }^{5}$ Engineering Ceramics Department, \\ Powder and Ceramics Division, \\ Korea Institute of Materials Science, \\ Changwon, Republic of Korea \\ *These authors contributed equally \\ to this work
}

Correspondence: Sang-Hyun Kim Department of Pharmacology, School of Medicine, Kyungpook National University, I0I Dong-In, Jung-Gu, Daegu 700-422, Republic of Korea Fax +82 534234838

Email shkim72@knu.ac.kr

Hui-Suk Yun

Engineering Ceramics Department, Powder and Ceramics Division, Korea Institute of Materials Science, 797

Changwondaero, Changwon 64I-83I,

Republic of Korea

Fax +82 552803392

Email yuni@kims.re.kr
Background: Mesoporous silica (MPS) nanoparticles (NPs), which have a unique pore structure and extremely large surface area and pore volume, have received much attention because of their biomedical application potential. Using MPS NPs for biomedical devices requires the verification of their biocompatibility because the surface area of NPs is one of the most important determinants of toxicity, including the cellular uptake and immune response. We have previously reported that the cytotoxicity and inflammation potential of MPS NPs have been shown to be lower than those of general amorphous colloidal silica (Col) NPs in macrophages, but the low cytotoxicity does not guarantee high biocompatibility in vivo. In this study, we compared the in vivo immunotoxicity of MPS and Col NPs in the mouse model to define the effects of pore structural conditions of silica NPs.

Materials and methods: Both MPS and Col NPs (2, 20, and $50 \mathrm{mg} / \mathrm{kg} /$ day) were intraperitoneally administered in female BALB/c mice for 4 weeks, and clinical toxicity, lymphocyte population, serum $\operatorname{IgG} / \operatorname{IgM}$ levels, and histological changes were examined.

Results: There was no overt sign of clinical toxicity in either MPS- or Col-treated mice. However, MPS NPs led to significant increases in liver and spleen weight and splenocyte proliferation. Mice treated with MPS NPs showed altered lymphocyte populations $\left(\mathrm{CD}^{+}\right.$, $\mathrm{CD}^{2} 5^{+}, \mathrm{CD}^{+}$, and $\mathrm{CD}^{+}$) in the spleen, increased serum $\mathrm{IgG}$ and IgM levels, and histological changes. Despite slight changes in lymphocyte populations in the spleen, Col NPs did not alter other immunological factors.

Conclusion: The results indicate that in vivo exposure to MPS NPs caused more damage to systemic immunity than that of Col NPs through the dysregulation of the spleen. The results for in vivo data are inconsistent with those for in vitro data, which show lower cytotoxicity for MPS NPs. These results suggest the importance of verifying biocompatibility both in vitro and in vivo during the design of new nanomaterials.

Keywords: immunotoxicity, mesoporous silica nanoparticle, colloidal silica nanoparticle, spleen

\section{Introduction}

Any advancements in nanomaterials, which are engineered structures with at least one dimension measuring $100 \mathrm{~nm}$ or less, require parallel efforts to understand their health and environmental effects. ${ }^{1}$ Silica $\left(\mathrm{SiO}_{2}\right)$ nanoparticles (NPs), which represent a typical nanomaterial, have been used in various applications, such as chemical mechanical polishing, varnishes, cosmetics, food, and biomedical devices. ${ }^{2,3}$ Mesoporous silica (MPS) NPs are designed to have increased the surface areas and pore volumes, and to arrange pore structure as compared to amorphous colloidal silica (Col) NPs. ${ }^{4}$ Studies have suggested that, by taking advantage of these characteristics, 
MPS NPs have the potential to be used as novel biomedical devices and in applications such as matrices for drug/gene delivery, biosensors, imaging for diagnosis, and tissue engineering. ${ }^{5,6}$ In addition, their unique pore structure properties show biological responses different from those of their bulk counterparts. The unusual physicochemical properties of silica NPs can be attributed to their surface area, size distribution, impurity, crystallinity, electronic properties, surface properties, solubility, aggregation, and shape. $^{7}$

Although silica is generally considered to be noncytotoxic, ${ }^{8}$ designing silica as nanomaterials may change its biocompatibility because of changes in its physicochemical properties, and its use for biomedical devices should be verified. ${ }^{7,9,10}$

A previous study of the biocompatibility of MPS has investigated the general effects of nanomaterials such as size, surface charge, concentration, and morphology. ${ }^{11}$ However, the largest expected influence on the difference in biocompatibility between MPS and Col NPs is the pore structure property. Changes in the pore structure can have considerable influence on biological responses because of its high reactivity. ${ }^{12}$ In this regard, we previously compared the effects of MPS and Col NPs on apoptosis and inflammation, and MPS NPs have been found to show better biocompatibility in vitro than Col NPs. ${ }^{4}$ However, the results of an in vitro study cannot guarantee biocompatibility in vivo, and therefore data from in vitro studies may be misleading and require verification through animal experiments. In vivo systems are extremely complicated and interactions between NPs and biological components such as proteins and cells can lead to unique biodistribution, clearance, and immune response. ${ }^{13,14}$ In addition, there is no study that has examined the effects of the pore structure property of NPs on immunotoxicity in vivo.

The present study compares the repeated-dose toxicity of two types of silica NPs (MPS and Col) in mice for 4 weeks (5 days/week) by focusing on the reticuloendothelial system (RES), which is part of the immune system that consists of phagocytic cells located in reticular connective tissue. RES organs such as the liver, spleen, and lymph nodes have been found to have a predisposition toward the rapid recognition and clearance of nanomaterials. ${ }^{15,16}$ Although previous studies have attempted to help NPs be hidden from the RES by employing various strategies such as polyethylene glycol conjugation, RES organs remain well-recognized as major NP targets. ${ }^{17,18}$ Therefore, there is a need for a better understanding of the relationship between the pore structure property of silica NPs and immune system organs such as the liver, spleen, and thymus for the bioapplication of MPS NPs.

\section{Materials and methods Nanoparticle preparation}

MPS and Col NPs were prepared using a similar process, except for the addition of the ionic surfactant cetyl trimethylammonium bromide (CTAB), as a template to MPS. The MPS NPs were prepared under dilute tetraethyl orthosilicate (TEOS) and a low surfactant concentration condition, as follows: $0.66 \mathrm{~g}$ of CTAB was dissolved in a mixture of $800 \mathrm{~mL}$ of distilled water and $26.4 \mathrm{~mL}$ of ammonium hydroxide (29 wt $\%$ $\mathrm{NH}_{3}$ in water); $3 \mathrm{~mL}$ of TEOS was then carefully added, with vigorous stirring. The precursor solution was stirred for another 3 hours at room temperature. To remove the surfactant template, the synthesized MPS was refluxed in a solution of $1 \mathrm{~mL}$ of $\mathrm{HCl}(37.4 \%)$ and $100 \mathrm{~mL}$ of methanol, followed by repeated (10 times, in general) washing with methanol and water. The surfactant-removed MPS NPs were placed in ethanol and sonicated before using, to prevent aggregation of NPs. The Col NPs were synthesized in a similar process to the MPS NPs by mixing $500 \mathrm{~mL}$ of ethanol, $20 \mathrm{~mL}$ of distilled water, $20 \mathrm{~mL}$ of ammonium hydroxide, and $30 \mathrm{~mL}$ of TEOS. The precursor solution was then stirred for 24 hours and filtered, washed with water, and re-dispersed in ethanol.

\section{Structural characterization}

The structural characterization was carried out by field emission scanning electron microscopy (JEOL5800, $5 \mathrm{kV}$; JEOL, Tokyo, Japan) and transmission electron microscopy (JEOL-JEM2100F, 200 kV; JEOL). The specific surface area and pore volume were measured by the $\mathrm{N}_{2}$-gas adsorption method, using a BET apparatus (Belsorp mini II; BEL Japan, Osaka, Japan).

\section{Animal care and handling}

Inbred female BALB/c mice, 6 weeks of age and with an average body weight of 19-21 g, were procured from Dae-Han Experimental Animal Center (Daejeon, Korea). Mice were randomly assigned to treatment groups (five per cage) and acclimatized for 1 week in the housing facility maintained at $23^{\circ} \mathrm{C} \pm 1^{\circ} \mathrm{C}$ with a 12 hour $/ 12$ hour light/dark cycle. Mice were housed in polycarbonate shoebox-style cages lined with Harlan Tekiad Laboratory Grade Sani-chips (Harlan Tekiad, Madison, WI, USA), which were changed every other day. Rodent chow (Superfeed Co, Wonju, Korea) and purified water (Milli-Q Water Purification system; 
Millipore, Bedford, MA, USA) were supplied ad libitum. Food and water consumption, as well as body weight gain, were recorded daily. All procedures involving the use of animals were approved by the Institutional Care and Use Committee and carried out in accordance with the guidelines established by the Public Health Service Policy on the Humane Care and Use of Laboratory Animals, Kyungpook National University, Daegu, Republic of Korea.

\section{Treatment}

The animals received silica NPs suspended in distilled water. Mice were intraperitoneally injected with silica NPs $(2,20$, and $50 \mathrm{mg} / \mathrm{kg} /$ day) for 4 weeks ( 5 days/week). At the end of the treatment period, the mice were fasted overnight and euthanized by carbon dioxide. Trunk blood was collected, and various organs were aseptically excised and weighed.

\section{Preparation of single-cell lymphocyte populations}

Single-cell lymphocyte populations were prepared from the spleen and thymus as described earlier ${ }^{19}$ with modifications as noted below. The spleen and thymus were aseptically excised and maintained in $10 \mathrm{~mL}$ of cold complete Roswell Park Memorial Institute (RPMI) medium (RPMI 1640 with 10\% heat-inactivated fetal bovine serum and $1 \%$ antibiotics [Gibco, Grand Island, NY, USA]). Monocellular suspensions were prepared using a Stomacher laboratory blender (Stomacher 80; Seward, Thetford, UK). The cell suspension was washed with RPMI medium. The cell pellets were resuspended in RPMI medium and incubated for 4 hours in $5 \% \mathrm{CO}_{2}$ at $37^{\circ} \mathrm{C}$. To collect lymphocytes, the suspended cells were transferred to a new tube separating macrophages and granulocytes. Viable cells were counted using a hemocytometer (Paul Marienfeld $\mathrm{GmbH}$ and Co. KG, Lauda-Königshofen, Germany).

\section{Proliferation assay}

The proliferation of splenocytes and thymocytes was determined by 3-(4,5-dimethylthiazol-2-yl)-2,5diphenyltetrazolium bromide (MTT) assay. At the end of the animal treatment, isolated splenocytes and thymocytes were dispensed into 96-well plates containing mitogens in either $10 \mu \mathrm{g} / \mathrm{mL}$ concanavalin $\mathrm{A}$ (Con A) or lipopolysaccharide (LPS). Cells were incubated for 72 hours followed by MTT for 4 hours, and then $100 \mu \mathrm{L}$ of dimethyl sulfoxide was added to dissolve the formazan crystals. The absorbance was read at $570 \mathrm{~nm}$ using the Biochrom Anthos $2010 \mathrm{spec}-$ trophotometer (Biochrom Ltd, Cambridge, UK).

\section{Phenotyping of splenic and thymic lymphocytes}

A flow cytometer (BD Biosciences, San Jose, CA, USA) was used to determine the prevalence of specific lymphocyte populations in the spleen and thymus as described earlier. ${ }^{20}$ Monoclonal antibodies were conjugated with fluorescein isothiocyanate ([FITC] emission at $525 \mathrm{~nm}$ ) or phycoerythrin ([PE] emission at $575 \mathrm{~nm}$ ). Antibodies to cell-specific receptors (Sasnta Cruz Biotechnology, Santa Cruz, CA, USA) included hamster anti-mouse CD3FITC (T lymphocyte), rat anti-mouse CD45R/B220-PE (B lymphocyte), rat anti-mouse CD4-FITC ( T helper lymphocyte), and rat anti-mouse CD8-PE (T cytotoxic/ suppressor lymphocyte). Cells were washed with phosphate-buffered saline. Antibodies were added to samples, gently vortexed, and followed by incubation for 30 minutes at $4{ }^{\circ} \mathrm{C}$.

\section{Measurement of serum immunoglobulin G (lgG) and immunoglobulin M (lgM)}

Immunoglobulin levels were analyzed using a mouse IgG and IgM enzyme-linked immunsorbent assay (ELISA) Quantitation Kit (Bethyl Laboratories, Montgomery, TX, USA) following the manufacturer's instructions. Briefly, 96-well plates were coated with affinity purified mouse IgG and IgM coating antibody. After overnight incubation at $4^{\circ} \mathrm{C}$, the plates were washed with wash buffer and blocked for 30 minutes in blocking solution. Samples or standards (IgG and $\operatorname{IgM}$ ) were added to each well and incubated at room temperature for 1 hour. After incubation, horseradish peroxidase detection antibodies were added to each well and incubated at room temperature for 1 hour; the plates were washed, developed by adding 3,3',5,5'-tetramethylbenzidine substrate solution $(100 \mu \mathrm{L})$, and incubated for 15 minutes. The reaction was stopped by adding sulfuric acid $(100 \mu \mathrm{L}$, $0.18 \mathrm{M}$ ) and the absorbance at $450 \mathrm{~nm}$ was measured with an ELISA reader.

\section{Histology}

The histology of the liver and spleen were determined by light microscopy as previously described. ${ }^{21}$ Liver and spleen tissues were fixed in 4\% formalin for 16 hours and embedded in paraffin. The paraffin-embedded samples were sectioned at $4 \mu \mathrm{m}$ thickness and then stained with hematoxylin and eosin. The slides were examined with light microscopy by two pathologists (Dr Shin and Dr Lee), independently. 


\section{Statistical analysis}

Statistical analyses were performed using SAS statistical software (SAS institute, Cary, NC, USA). Treatment effects were analyzed using ANOVA, followed by Dunnett's multiple range tests. Significance was set at $P<0.05$.

\section{Results}

\section{Characterization of materials}

According to the images of MPS and Col NPs in Figure 1, both showed the same spherical morphology (approximately $100 \mathrm{~nm}$ in diameter) and were clearly discrete. Both NPs showed narrow particle size distribution at $98 \pm 6 \mathrm{~nm}$ and $102 \pm 6 \mathrm{~nm}$ for MPS and Col, respectively (Figure S1). However, MPS NPs were composed of a 2D hexagonally well-ordered mesostructure, the average pore size of which was $2.4 \mathrm{~nm}$, and their specific surface area and pore volume were $1150 \mathrm{~m}^{2} / \mathrm{g}$ and $1.46 \mathrm{~cm}^{3} / \mathrm{g}$, respectively. On the other hand, Col NPs had no mesopore structure, and their specific surface area and pore volume were $40 \mathrm{~m}^{2} / \mathrm{g}$ and $0.29 \mathrm{~cm}^{3} / \mathrm{g}$, respectively. ${ }^{4}$

\section{Clinical manifestation and blood biochemical assay}

For the repeated administration experiment, female BALB/c mice were intraperitoneally administered with MPS and Col NPs (2, 20, and $50 \mathrm{mg} / \mathrm{kg} /$ day) for 4 weeks (5 days/week).

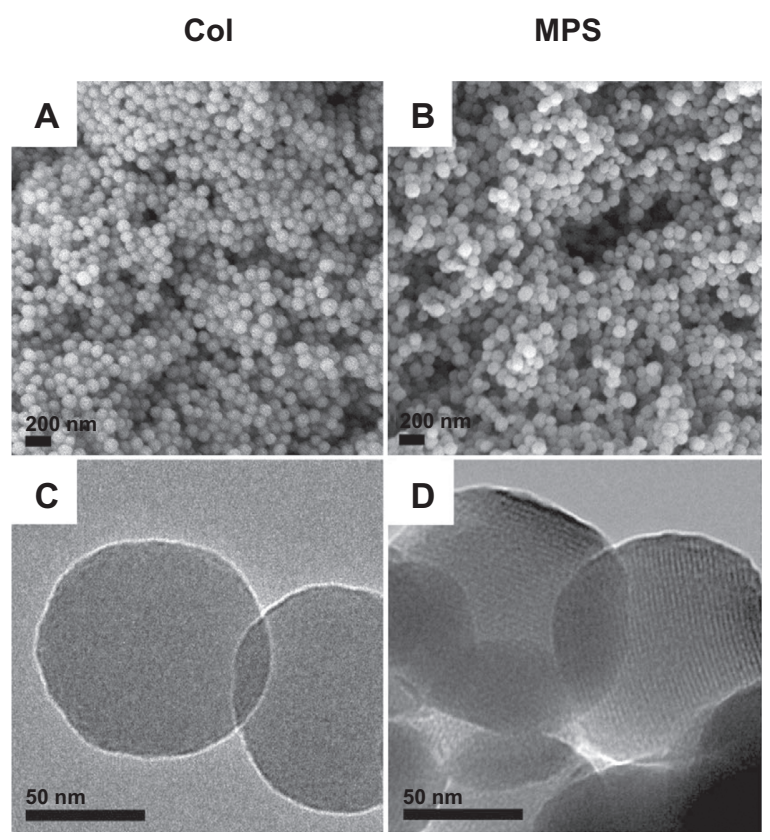

Figure I (A and B) FE-SEM and (C and D) TEM images of Col and MPS NPs. Abbreviations: FE-SEM, field emission scanning electron microscopy; TEM, transmission electron microscopy; MPS, mesoporous silica; Col, colloidal silica; NPs, nanoparticles.
No overt clinical toxicity or behavioral changes were observed during the treatment period, and no significant changes in body weight were observed between treatment groups (Figure 2). Only the group treated with $50 \mathrm{mg} / \mathrm{kg} /$ day of Col NPs showed increased food consumption, and water

A

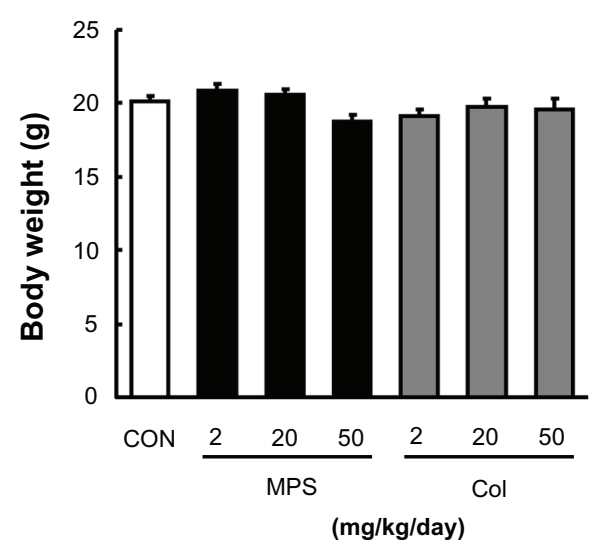

B

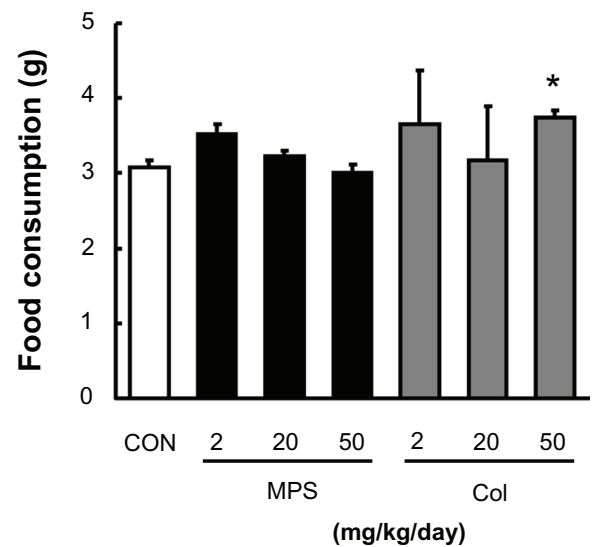

C

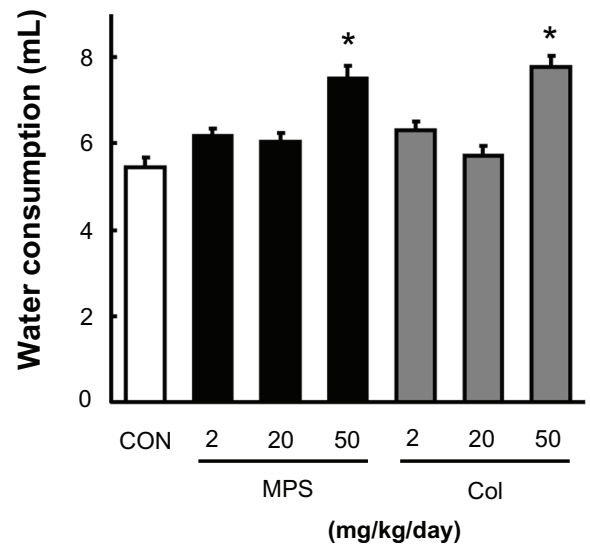

Figure 2 Effects of MPS and Col NPs on (A) body weight, (B) food consumption, and $(\mathbf{C})$ water consumption in female BALB/c mice.

Notes: MPS and Col NPs were intraperitoneally administered to mice at doses of 2,20 , or $50 \mathrm{mg} / \mathrm{kg} /$ day for 4 weeks ( 5 days/week). The results are presented as mean $\pm S E(n=5)$. $* P<0.05$ : significantly different from the control group values. Abbreviations: MPS, mesoporous silica; Col, colloidal silica; NPs, nanoparticles; CON, control; SE, standard error. 
consumption increased in both of the treatment groups that were administered $50 \mathrm{mg} / \mathrm{kg} /$ day silica NPs.

The effects of MPS and Col NPs on the weight of the liver, kidney, spleen, and thymus were examined (Table 1). A high MPS dose significantly increased the relative weight of the liver and spleen. However, Col NPs had no effect on the weight of the liver and spleen. MPS and Col NPs had no effects on the weight of the kidney and thymus.

Previous studies have proposed the hepatotoxic potential of silica NPs. ${ }^{1,22}$ Therefore, the hepatotoxic potential of MPS and Col NPs was examined through an animal experiment. Histologically, occasional spotty necrosis and focal sinusoidal dilatation with hemorrhage were observed in the liver tissue of both MPS and Col treated mice (Figure S2). By contrast, neither NP influenced the serum aspartate transaminase and alanine transaminase levels, as a marker of liver toxicity, or creatinine and blood urea nitrogen levels, as a marker of kidney toxicity, (Table S1). Although there was an increase in liver weight in MPS treated mice, this increase was observed only at the highest MPS dose (Table 1). Taken together, the results indicate the weak hepatotoxic potential of both NPs.

\section{Cell proliferation and lymphocyte population in immune organs}

The toxic effects of MPS and Col NPs on immune organs (spleen and thymus) were examined. As shown in Figure 3A, in the spleen, continuous exposure to MPS NPs led to dose-dependent increases in proliferative responses to the lymphocyte mitogens, Con A or LPS. Treatment with 20 and $50 \mathrm{mg} / \mathrm{kg} /$ day of MPS NPs showed 2.2- and 3.3-fold increases, respectively, in proliferation for Con A and 2.4and 4.4-fold increases, respectively, for LPS in comparison

Table I Effects of MPS and Col NPs on organ weight of female $\mathrm{BALB} / \mathrm{c}$ mice

\begin{tabular}{|c|c|c|c|c|}
\hline \multirow{2}{*}{$\begin{array}{l}\text { Dose of } \\
\text { nanoparticles } \\
\text { (mg/kg/day) }\end{array}$} & \multicolumn{4}{|c|}{$\begin{array}{l}\text { Organ weight/body weight ratio } \\
(\mathrm{g} / 100 \mathrm{~g}) \text { for }\end{array}$} \\
\hline & Liver & Kidney & Spleen & Thymus \\
\hline $\mathrm{CON}$ & $4.62 \pm 0.04$ & $1.58 \pm 0.03$ & $0.38 \pm 0.01$ & $0.32 \pm 0.02$ \\
\hline MPS 2 & $4.75 \pm 0.10$ & $1.51 \pm 0.02$ & $0.34 \pm 0.03$ & $0.24 \pm 0.01$ \\
\hline MPS 20 & $4.87 \pm 0.17$ & $1.48 \pm 0.02$ & $0.45 \pm 0.04^{*}$ & $0.37 \pm 0.04$ \\
\hline MPS 50 & $5.25 \pm 0.1 I^{*}$ & $1.37 \pm 0.10$ & $0.70 \pm 0.02 *$ & $0.39 \pm 0.01$ \\
\hline Col 2 & $4.29 \pm 0.11$ & $1.41 \pm 0.07$ & $0.32 \pm 0.02$ & $0.28 \pm 0.03$ \\
\hline Col 20 & $4.02 \pm 0.06$ & $1.35 \pm 0.03$ & $0.37 \pm 0.02$ & $0.27 \pm 0.01$ \\
\hline Col 50 & $4.18 \pm 0.20$ & $1.40 \pm 0.07$ & $0.37 \pm 0.03$ & $0.25 \pm 0.03$ \\
\hline
\end{tabular}

Notes: The results are presented as mean \pm SE $(n=5)$. ${ }^{*} P<0.05$ : significantly different from the control group values.

Abbreviations: MPS, mesoporous silica; Col, colloidal silica; NPs, nanoparticles; CON, control; SE, standard error.
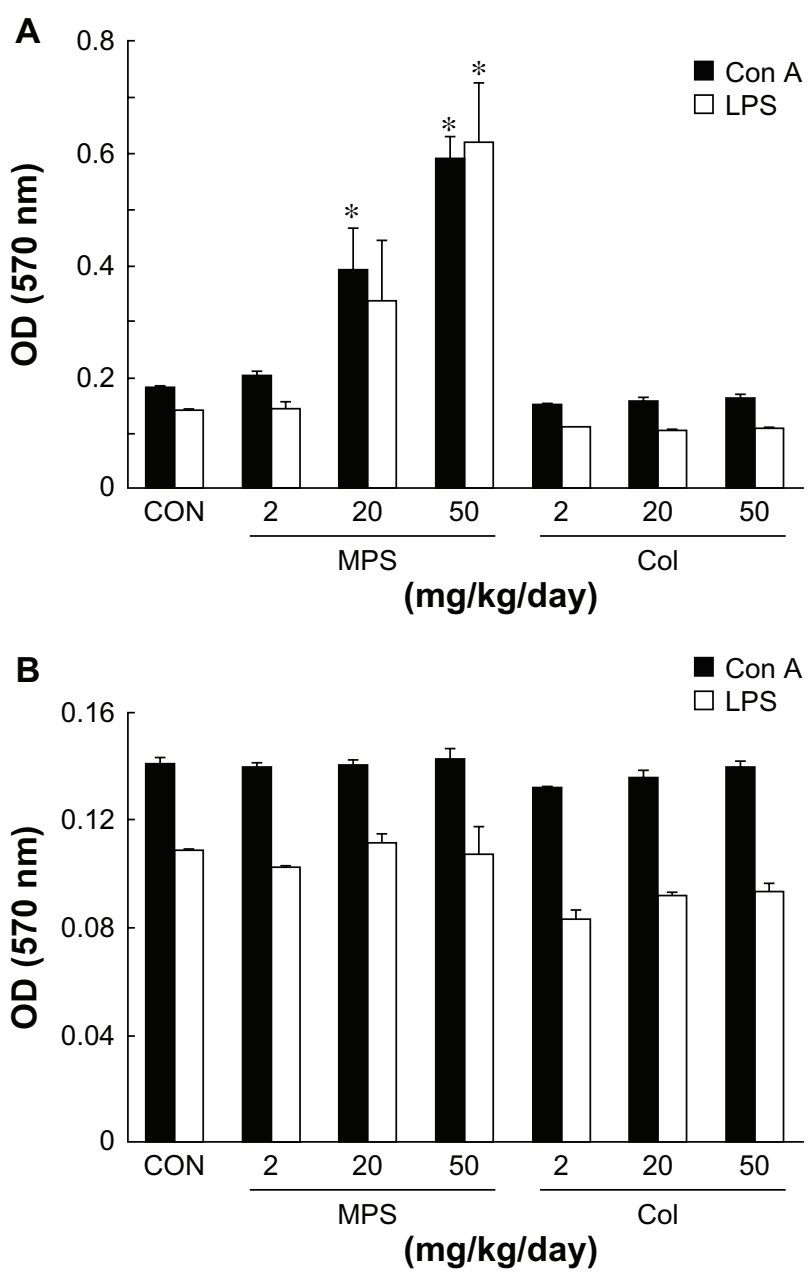

Figure 3 Proliferation assays of (A) splenocytes and (B) thymocytes in mice treated with MPS and Col NPs.

Notes: MPS and Col NPs were intraperitoneally administered to mice at doses of 2,20 , or $50 \mathrm{mg} / \mathrm{kg} /$ day for 4 weeks (5 days/week). Splenocytes and thymocytes were isolated and cultured into 96-well plates containing mitogens, either Con A ( $10 \mu \mathrm{g} / \mathrm{mL})$ or LPS (10 $\mathrm{gg} / \mathrm{mL})$, for 72 hours and evaluated for their proliferation using MTT assay. The results are presented as mean \pm SE $(n=5)$. $* P<0.05$ : significantly different from the control group values.

Abbreviations: MPS, mesoporous silica; Col, colloidal silica; NPs, nanoparticles; CON, control; Con A, concanavalin A; LPS, lipopolysaccharide; MTT, 3-(4,5-dimethylthiazol2-yl)-2,5-diphenyltetrazolium bromide; OD, optical density; SE, standard error.

with the control after 72 hours, whereas no increase was observed for Col NPs. In the thymus, no changes in thymocyte proliferation were observed for both MPS and Col NPs (Figure 3B).

Silica NPs altered lymphocyte populations and phenotypes in the spleen. Intraperitoneal exposure to MPS NPs at doses of 2, 20, and $50 \mathrm{mg} / \mathrm{kg} /$ day led to 2.3-, 4.6-, and 5.1fold increases, respectively, in $\mathrm{CD} 45^{+} \mathrm{B}$ lymphocytes in the spleen (Figure 4A). Col NPs increased CD45 ${ }^{+}$B lymphocytes in the spleen, although not as much as MPS NPs. Neither NP had an effect on the population of $\mathrm{CD}^{+} \mathrm{T}$ lymphocytes (Figure 4B). Next, the phenotype of T lymphocytes in the spleen was examined. Figure $4 \mathrm{C}-\mathrm{F}$ show the changes in this 
A

C
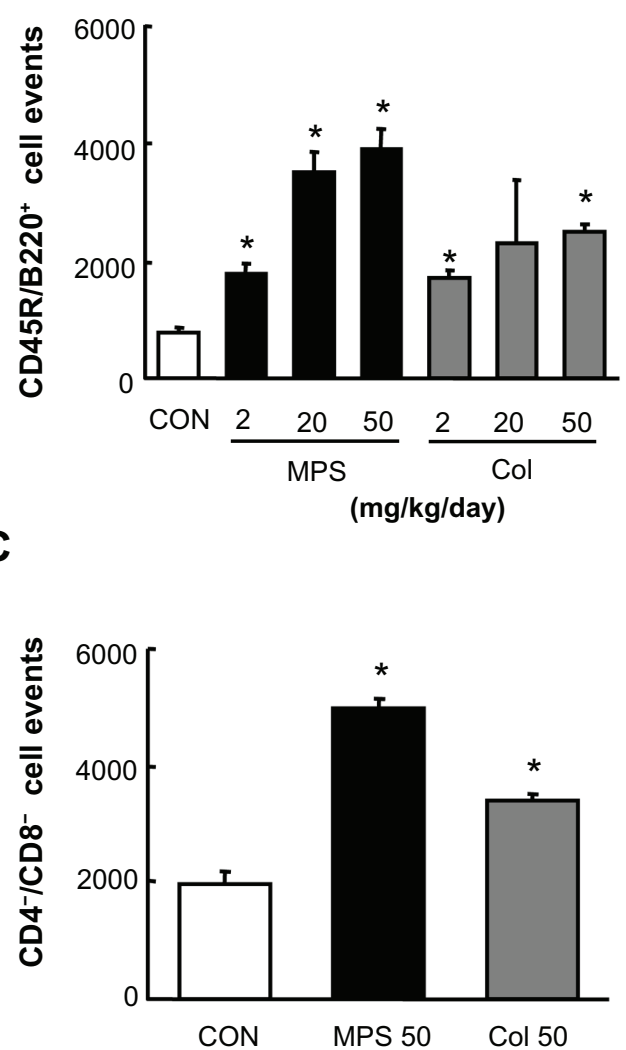

E

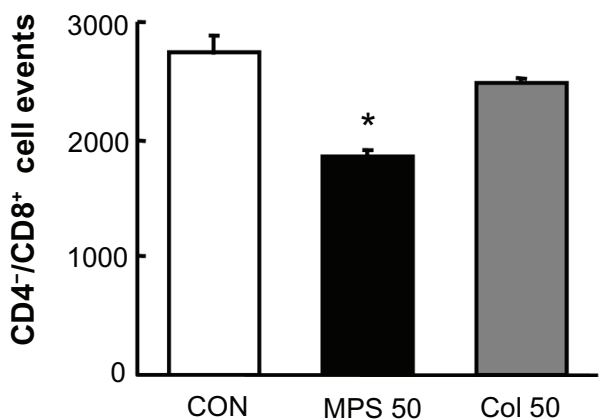

B

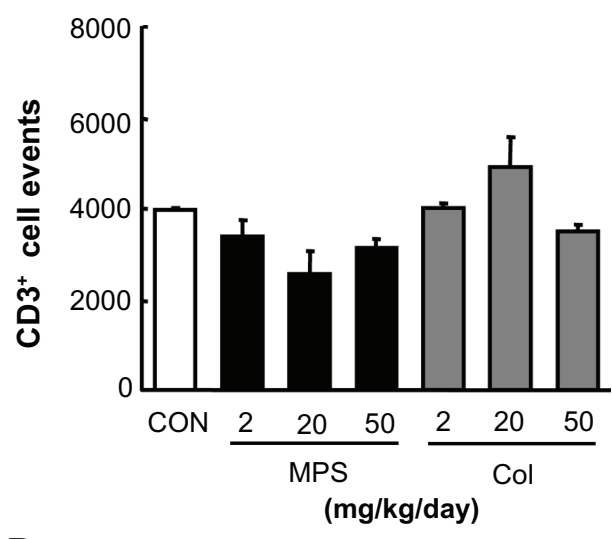

D

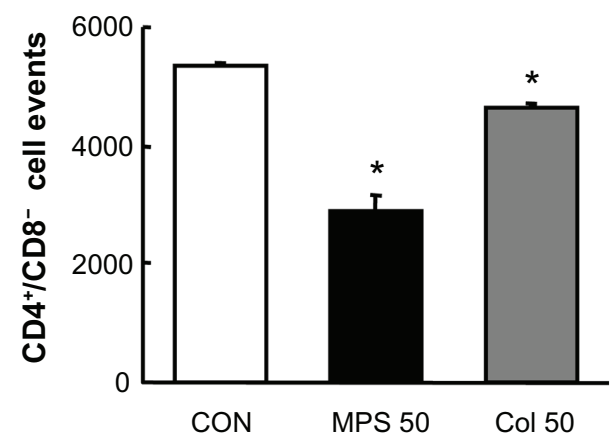

F

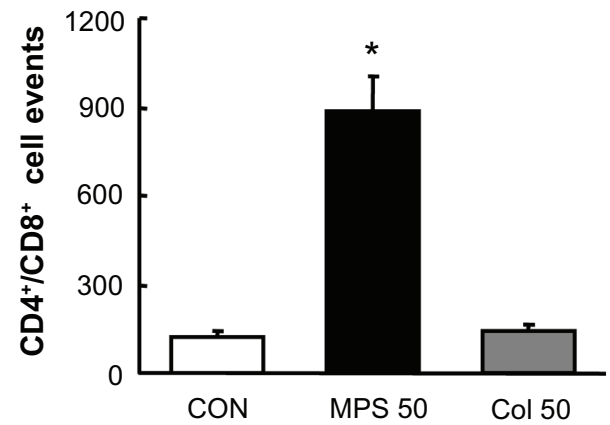

Figure 4 Effects of MPS and Col NPs on lymphocyte populations in the spleen. (A and B) MPS and Col NPs were intraperitoneally administered to mice at a dose of 2, 20, or $50 \mathrm{mg} / \mathrm{kg} /$ day. Effects of MPS and Col NPs on B- and T-lymphocyte populations, respectively. Populations are shown as absolute cell counts for given receptors. (C-F) Effects of MPS and Col NPs (50 mg/kg/day) on T-lymphocyte phenotype populations, respectively. Populations show as absolute cell counts for given receptors.

Notes: The results are shown as mean $\pm S E(n=5)$. $* P<0.05$ : significantly different from the control group.

Abbreviations: MPS, mesoporous silica; Col, colloidal silica; NPs, nanoparticles; CON, control; SE, standard error.

phenotype (helper and cytotoxic T cells). Exposure to MPS NPs led to the dramatic restructuring of the population of T lymphocytes. MPS NPs increased $\mathrm{CD}^{-} / \mathrm{CD}^{-}$and $\mathrm{CD}^{+} /$ $\mathrm{CD} 8^{+}$phenotypes, but decreased $\mathrm{CD} 4^{+} / \mathrm{CD} 8^{-}$and $\mathrm{CD} 4^{-} / \mathrm{CD} 8^{+}$ phenotypes. Col NPs also induced some changes, although not as much as MPS NPs. Lymphocyte populations and thymus phenotypes remained unchanged by both MPS and Col NPs (Figure S3).

\section{Histopathological examination}

Histological examination was performed to confirm the serological differences found in the above studies (splenocyte proliferation and lymphocyte population) in the tissue section (Figure 5). In the spleen tissues of the vehicle control animals, several distinct white pulps of variable size were interwoven by the filtering red pulp. On the other hand, red pulp expansion with many macrophage infiltration and 


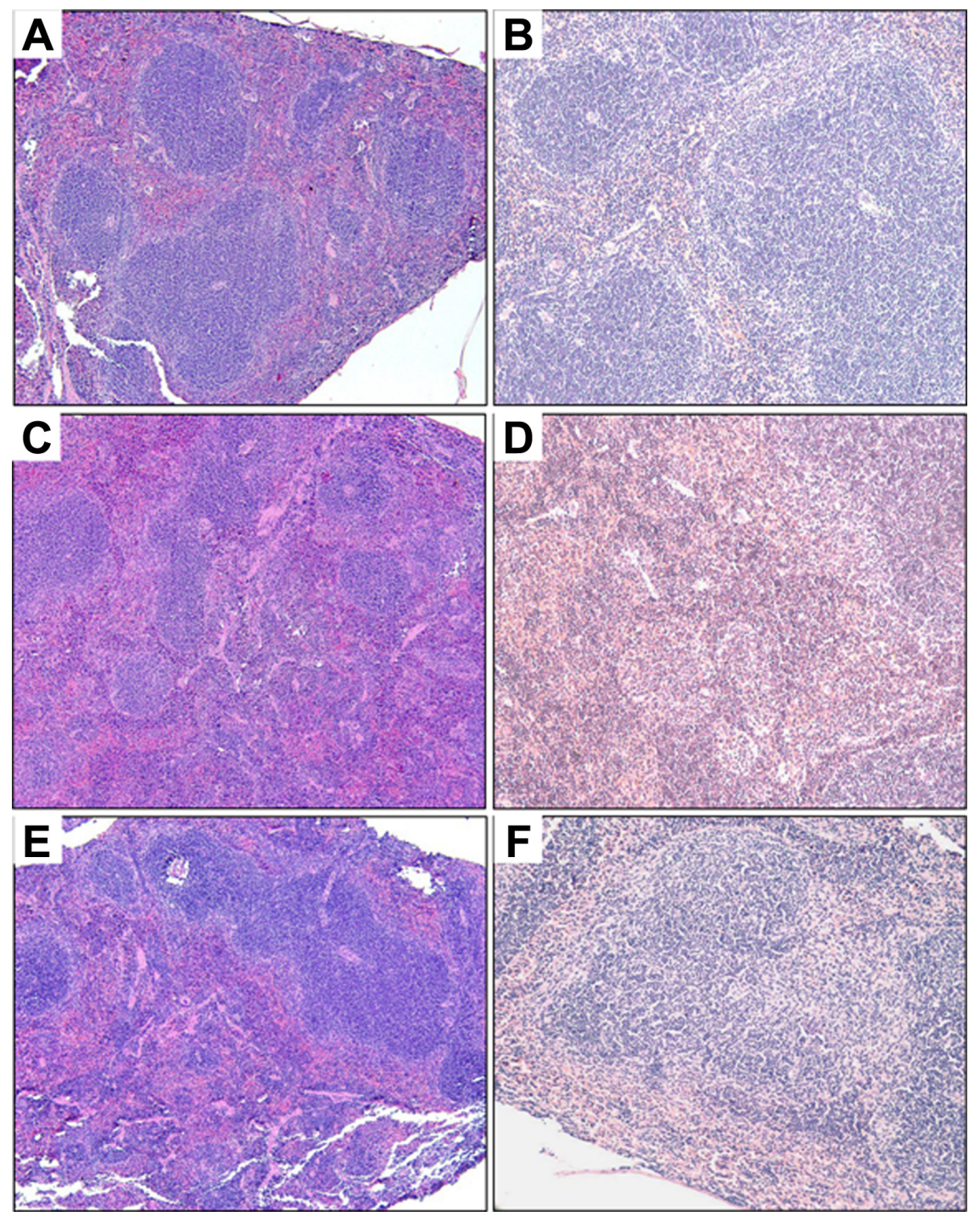

Figure 5 Histological analysis of the spleen. Micromorphological changes in the spleen after treatment with MPS and Col NPs at a dose of 50 mg/kg/day for 4 weeks ( 5 days/week). Spleen sections were stained with H\&E. (A and B) Control; (C and D) $50 \mathrm{mg} / \mathrm{kg} /$ day of MPS NPs; (E and F) $50 \mathrm{mg} / \mathrm{kg} / \mathrm{day}$ of Col NPs. Original magnification $(\mathbf{A}, \mathbf{C}$, and F) $\times 200$; (B, D, and E) $\times 400$.

Abbreviations: MPS, mesoporous silica; Col, colloidal silica; NPs, nanoparticles; H\&E, hematoxylin and eosin.

relative white pulp shrinkage was observed in high-dose MPS-NP treated groups. In Col NPs treated groups, white pulps appeared to fuse with one another. Neither red pulp expansion nor increased macrophage infiltration was evident in Col NPs treated groups.

\section{Immunoglobulin production in serum}

For an analysis of the systemic immune response, the serum level of immunoglobulins was observed in mice administered with MPS and Col NPs (Figure 6). Previous studies have shown that IgG and IgM can bind to various pathogens and protect the body against them through agglutination and immobilization, complement activation (classical pathway), opsonization for phagocytosis, and the neutralization of their toxins. There were significant increases in $\mathrm{IgG}$ and IgM levels in MPS-treated mice at doses of 20 and $50 \mathrm{mg} / \mathrm{kg} /$ day. However, Col-treated mice showed no changes in these levels, although there were slight increases in $\mathrm{CD} 45^{+} \mathrm{B}$ lymphocytes.

\section{Discussion}

MPS NPs have the potential to be drug delivery vehicles and may be used for other biomedical applications. Some studies have shown that polyethylene glycol conjugation is the most efficient modification strategy for minimizing immune responses to biomedical applications. Polyethylene glycols can form a hydrophilic layer around particles with increased dispersity, and can greatly increase the half-life by delaying opsononization..$^{23}$ However, the potential adverse effect of MPS NPs on biological systems, specifically the immune 

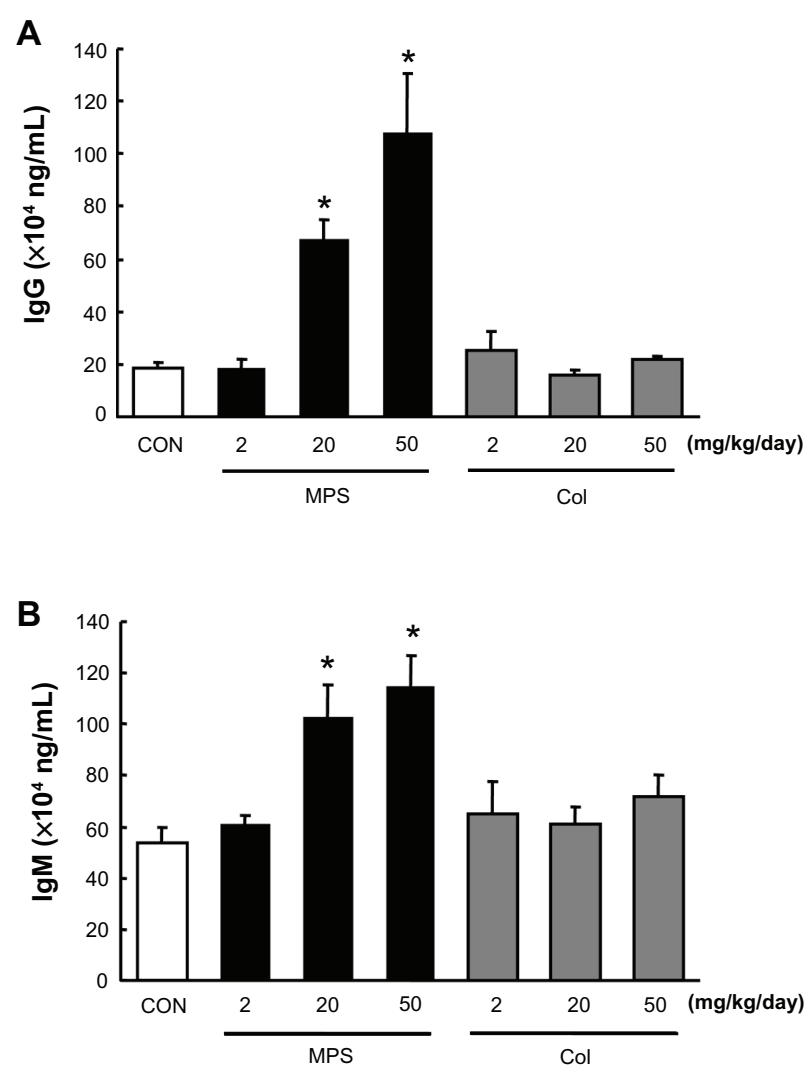

Figure 6 Effects of MPS and Col NPs on the secretion of $\operatorname{lgG}$ and IgM in the serum. The secretion of (A) $\lg G$ and (B) $\lg M$ was measured using ELISA, as described in the Materials and methods section.

Notes: The results are shown as mean $\pm S E(n=5)$. ${ }^{*} P<0.05$ : significantly different from the control group.

Abbreviations: MPS, mesoporous silica; Col, colloidal silica; NPs, nanoparticles; IgG, immunoglobulin G; IgM, immunoglobulin M; CON, control; ELISA, enzymelinked immunosorbent assay; SE, standard error.

system, is currently not well understood and awaits further investigation. ${ }^{24} \mathrm{~A}$ clear understanding of adverse effects of new materials is essential for their commercialization in the biomedical market. We previously studied the effects of pore structural properties of silica NPs on cytotoxicity and inflammation in vitro and found that highly porous MPS NPs can better reduce cytotoxicity, inflammation, and hypersensitivity than Col NPs because of the reduced activation of mitogen-activated protein kinases, NF- $\kappa \mathrm{B}$, and caspases. ${ }^{4}$ In the present study, we compared the immunotoxicity of MPS and Col NPs in mice. Surprisingly, we observed the opposite toxicity of MPS and Col NPs in vitro.

Some studies have shown that silica NPs of various sizes induce pro-inflammatory responses ${ }^{25}$ and that the liver and spleen are major target organs for toxicity. ${ }^{26}$ The liver and spleen are RES organs and recognized as major NP targets. Silica NPs (70 and $100 \mathrm{~nm}$ ) cause hepatic injury in mice after intravenous administration. ${ }^{27,28}$ Some reports suggested that nano- and submicron-sized silica NPs are similar in terms of the severity of liver damage, which is dependent on the exposure dose, and that the mechanism underlying this toxicity is almost the same. ${ }^{1,22}$ In this study, both types of silica NPs induced mild liver damage based on increases in liver weight and histological analyses.

The spleen has been found to be one of the most important lymphoid organs involved in the initiation of immune responses. ${ }^{29,30}$ The spleen has a central function in the immune system and is highly sensitive to damage by xenobiotics..$^{21,31}$ Lymphocyte proliferation is an important phase in the immune response. ${ }^{32}$ The intraperitoneal inoculation of nanosized bioceramic particles $(30 \mathrm{~nm})$ in mice can function as an efficient gene delivery vehicle specifically for the spleen. ${ }^{33}$ In the present study, although there were no changes in body weight, relative spleen weight and splenocyte proliferation increased in mice treated with MPS NPs. These results suggest that the intraperitoneal injection of MPS NPs can cause immunotoxicity and that the spleen is the target organ.

The spleen has two distinct components: red pulp and white pulp. ${ }^{31}$ White pulp contains mainly lymphocytes and is responsible for the immunological response. The histopathological results indicate that the spleen of mice treated with MPS NPs showed a decrease in white pulp and an increase in the number of macrophages. A significant increase in the area of lymphoid follicles and increased cellular density were observed. These results suggest that MPS NPs may cause mild inflammation and T-cell maturation in the spleen. In addition, exposure to MPS NPs significantly increased B-lymphocyte $\left(\mathrm{CD}^{4} 5^{+}\right)$and they led to increased $\mathrm{IgG} / \operatorname{IgM}$ responses in mice. IgG and IgM are dominant immunoglobulins in the serum and are important indices of the humoral immune function. After exposure to a pathogen, IgG plays a dominant role in humoral immunity and resists a variety of bacteria to protect the body from infection. IgM binds with complement to dissolve pathogens. ${ }^{34}$ A particularly striking immunological feature of individuals with silica exposure or silicosis is elevated $\operatorname{IgG}$ and $\operatorname{IgM}$ in blood. ${ }^{35}$ In the present study, the results indicating increased levels of IgG and IgM suggest that MPS NPs disordered the humoral immune function. In addition, although MPS NPs did not induce any significant changes in total T lymphocytes $\left(\mathrm{CD}^{+}\right)$, they led to significant changes in T-lymphocyte phenotypes. More specifically, there were significant increases in $\mathrm{CD}^{-/}$ $\mathrm{CD}^{-}$and $\mathrm{CD}^{+} / \mathrm{CD}^{+}$populations in mice treated with MPS NPs, reflecting the stimulated immature splenocytes. The results indicating decreased $\mathrm{CD}^{-} / \mathrm{CD}^{-}$and $\mathrm{CD}^{-} / \mathrm{CD}^{+}$ phenotypes suggest that MPS NPs cause the disruption of the CD4/CD8 inversion ratio. Although the CD4/CD8 inversion 
ratio is 2:1 in normal spleen, the mice treated with MPS NPs showed approximately a 3:2 ratio. Taken together, these results suggest that MPS NPs can induce dysregulation of lymphocyte population.

Silica has generally been considered to be noncytotoxic, and some studies have suggested that NPs can be applied to biomedicine because of their biosafety. ${ }^{36,37}$ Recent research has found that silica NPs with extremely large surface areas do not impair essential functional responses of human macrophages, including the engulfment of target cells and cytokine secretion. ${ }^{24}$ Previous studies have shown that mesoporous materials show low toxicity in primary human dendritic cells. ${ }^{38}$ By contrast, the cytotoxicity of Col NPs in cultured human lung cells and hepatocytes has been shown to increase in a time- and dose-dependent manner. ${ }^{3,39}$ In addition, MPS NPs have been found to produce greater reductions in cytotoxicity, inflammation, and hypersensitivity than Col NPs. ${ }^{4}$ However, in this study, despite slight changes in T- and B-lymphocyte populations in mice treated with Col NPs, Col NPs did not alter splenocyte proliferation, spleen weight, and serum IgG/IgM levels. By contrast, MPS NPs produced higher immunotoxicity than Col NPs. These results suggest that MPS NPs may cause more damage to the immunological function and the dysregulation of the spleen than Col NPs.

Differences in experimental conditions (eg, those between in vitro and in vivo studies) may cause differences in the toxicity of nanomaterials such as nano-C60 and nanoparticular iron complexes..$^{40,41}$ Because of hydrophilicity and silanols on the surface, MPS NPs bind easily to plasma proteins or blood cells. In addition, the masking of surface silanols through functionalization reduces the toxicity of MPS NPs. ${ }^{7}$ This suggests that MPS NPs may induce in vivo toxicity because of their surface properties (hydrophilicity and silanols) and large surface area. Although we try to compare the in vivo data with in vitro data, this comparison might be difficult, because different cell types were taken into consideration. Moreover, the way in which the particles were applied differs and also the fact that the in vivo experiments are performed by repeated intraperitoneal injection. The observed effects might therefore be due to differences in uptake and particle counts, since surface and size affect the uptake to a huge extent. However, an in vivo study is considered to be essential for assessing the biocompatibility and toxicity of nanomaterials. For a better understanding of the in vivo toxicity of MPS NPs and the underlying mechanism, future research should take a proteomic approach and target lymphocytes.

\section{Conclusion}

We compared the immunotoxicity of MPS and Col NPs in mice to examine the effects of pore structure conditions of silica NPs. MPS NPs increased spleen weight and splenocyte proliferation. Mice treated with MPS NPs showed changes in the lymphocyte population of the spleen, increased serum IgG/IgM levels, and histological changes. The results suggest that in vivo exposure to MPS NPs caused more damage to systemic immunity than Col NPs through the dysregulation of the spleen. These results for in vivo data are inconsistent with those for in vitro data, which show lower cytotoxicity for MPS NPs. Understanding these effects can not only guide the rational design of biocompatible particles but also provide insights into how systemic immunotoxicity can be induced. Therefore, researchers investigating NPs should carefully design their materials with consideration of toxicity tests both in vitro and in vivo to use them in bioapplication fields. In this regard, future research should employ this study's results to develop better drug-delivery systems using silica NPs.

\section{Acknowledgment}

This work was supported by the Mid-career Researcher Program through an NRF grant funded by the Korean Ministry of Education, Science and Technology (MEST) (No 2012-005709).

\section{Disclosure}

The authors report no conflicts of interest in this work.

\section{References}

1. Nishimori H, Kondoh M, Isoda K, Tsunoda S, Tsutsumi Y, Yagi K. Silica nanoparticles as hepatotoxicants. Eur J Pharm Biopharm. 2009;72(3): 496-501.

2. Bottini M, D'Annibale F, Magrini A, et al. Quantum dot-doped silica nanoparticles as probes for targeting of T-lymphocytes. Int J Nanomedicine. 2007;2(2):227-233.

3. Lin W, Huang YW, Zhou XD, Ma Y. In vitro toxicity of silica nanoparticles in human lung cancer cells. Toxicol Appl Pharmacol. 2006;217(3): 252-259.

4. Lee S, Yun HS, Kim SH. The comparative effects of mesoporous silica nanoparticles and colloidal silica on inflammation and apoptosis. Biomaterials. 2011;32(35):9434-9443.

5. Slowing II, Vivero-Escoto JL, Wu CW, Lin VS. Mesoporous silica nanoparticles as controlled release drug delivery and gene transfection carriers. Adv Drug Deliv Rev. 2008;60(11):1278-1288.

6. Yun HS, Kim SE, Hyeon YT. Design and preparation of bioactive glasses with hierarchical pore networks. Chem Commun (Camb). 2007;21: 2139-2141.

7. Zhao Y, Sun X, Zhang G, Trewyn BG, Slowing II, Lin VS. Interaction of mesoporous silica nanoparticles with human red blood cell membranes: size and surface effects. ACS Nano. 2011;5(2):1366-1375.

8. Cho M, Cho WS, Choi M, et al. The impact of size on tissue distribution and elimination by single intravenous injection of silica nanoparticles. Toxicol Lett. 2009;189(3):177-183. 
9. Guzman E, Liggieri L, Santini E, Ferrari M, Ravera F. Effect of hydrophilic and hydrophobic nanoparticles on the surface pressure response of DPPC Monolayers. J Phys Chem C. 2011;115(44):21715-21722.

10. Guzman E, Liggieri L, Santini E, Ferrari M, Ravera F. Influence of silica nanoparticles on dilational rheology of DPPC-palmitic acid Langmuir monolayers. Soft Matter. 2012;8(14):3938-3948.

11. Hudson SP, Padera RF, Langer R, Kohane DS. The biocompatibility of mesoporous silicates. Biomaterials. 2008;29(30):4045-4055.

12. Yun HS, Park JW, Kim SH, Kim YJ, Jang JH. Effect of the pore structure of bioactive glass balls on biocompatibility in vitro and in vivo. Acta Biomater. 2011;7(6):2651-2660.

13. Fischer HC, Chan WC. Nanotoxicity: the growing need for in vivo study. Curr Opin Biotechnol. 2007;18(6):565-571.

14. Liu T, Li L, Teng X, et al. Single and repeated dose toxicity of mesoporous hollow silica nanoparticles in intravenously exposed mice. Biomaterials. 2011;32(6):1657-1668.

15. Kagan VE, Bayir H, Shvedova AA. Nanomedicine and nanotoxicology: two sides of the same coin. Nanomedicine. 2005;1(4):313-316.

16. Linkov I, Satterstrom FK, Corey LM. Nanotoxicology and nanomedicine: making hard decisions. Nanomedicine. 2008;4(2):167-171.

17. Oberdörster G. Safety assessment for nanotechnology and nanomedicine: concepts of nanotoxicology. J Intern Med. 2010;267(1): 89-105.

18. Liu T, Li L, Fu C, Liu H, Chen D, Tang F. Pathological mechanisms of liver injury caused by continuous intraperitoneal injection of silica nanoparticles. Biomaterials. 2012;33(7):2399-2407.

19. Kim SH, Johnson VJ, Sharma RP. Oral exposure to inorganic mercury alters T lymphocyte phenotypes and cytokine expression in BALB/c mice. Arch Toxicol. 2003;77(11):613-620.

20. Son HY, Lee S, Tak EN, et al. Perfluorooctanoic acid alters T lymphocyte phenotypes and cytokine expression in mice. Environ Toxicol. 2009;24(6):580-588.

21. Son HY, Lee S, Park SB, et al. Toxic effects of mercuric sulfide on immune organs in mice. Immunopharmacol Immunotoxicol. 2010;32(2): $277-283$.

22. Lu X, Tian Y, Zhao Q, Jin T, Xiao S, Fan X. Integrated metabonomics analysis of the size-response relationship of silica nanoparticles-induced toxicity in mice. Nanotechnology. 2011;22(5):055101.

23. Veronese FM, Pasut G. PEGylation, successful approach to drug delivery. Drug Discov Today. 2005;10(21):1451-1458.

24. Witasp E, Kupferschmidt N, Bengtsson L, et al. Efficient internalization of mesoporous silica particles of different sizes by primary human macrophages without impairment of macrophage clearance of apoptotic or antibody-opsonized target cells. Toxicol Appl Pharmacol. 2009;239(3):306-319.

25. Park EJ, Park K. Oxidative stress and pro-inflammatory responses induced by silica nanoparticles in vivo and in vitro. Toxicol Lett. 2009; 184(1):18-25.
26. Nishimori H, Kondoh M, Isoda K, Tsunoda S, Tsutsumi Y, Yagi K. Histological analysis of 70-nm silica particles-induced chronic toxicity in mice. Eur J Pharm Biopharm. 2009;72(3):626-629.

27. Hasezaki T, Isoda K, Kondoh M, Tsutsumi Y, Yagi K. Hepatotoxicity of silica nanoparticles with a diameter of $100 \mathrm{~nm}$. Pharmazie. 2011;66(9): 698-703.

28. Li X, Kondoh M, Watari A, et al. Effect of 70-nm silica particles on the toxicity of acetaminophen, tetracycline, trazodone, and 5-aminosalicylic acid in mice. Pharmazie. 2011;66(4):282-286.

29. Mebius RE, Kraal G. Structure and function of the spleen. Nat Rev Immunol. 2005;5(8):606-616.

30. Tupin E, Poirier B, Bureau MF, et al. Non-viral gene transfer of murine spleen cells achieved by in vivo electroporation. Gene Ther. 2003;10(7): 569-579.

31. de Visser KE, Eichten A, Coussens LM. Paradoxical roles of the immune system during cancer development. Nat Rev Cancer. 2006;6(1): 24-37.

32. Sang X, Zheng L, Sun Q, et al. The chronic spleen injury of mice following long-term exposure to titanium dioxide nanoparticles. J Biomed Mater Res A. 2012;100(4):894-902.

33. Tan K, Cheang P, Ho IA, Lam PY, Hui KM. Nanosized bioceramic particles could function as efficient gene delivery vehicles with target specificity for the spleen. Gene Ther. 2007;14(10):828-835.

34. Schroeder HW Jr, Cavacini L. Structure and function of immunoglobulins. J Allergy Clin Immunol. 2010;125(2 Supp1 2):S41-S52.

35. Huang SH, Hubbs AF, Stanley CF, et al. Immunoglobulin responses to experimental silicosis. Toxicol Sci. 2001;59(1):108-117.

36. Vallhov H, Gabrielsson S, Strømme M, Scheynius A, Garcia-Bennett AE. Mesoporous silica particles induce size dependent effects on human dendritic cells. Nano Lett. 2007;7(12):3576-3582.

37. Huang DM, Chung TH, Hung Y, et al. Internalization of mesoporous silica nanoparticles induces transient but not sufficient osteogenic signals in human mesenchymal stem cells. Toxicol Appl Pharmacol. 2008;231(2):208-215.

38. Murdock RC, Braydich-Stolle L, Schrand AM, Schlager JJ, Hussain SM. Characterization of nanomaterial dispersion in solution prior to in vitro exposure using dynamic light scattering technique. Toxicol Sci. 2008;101(2):239-253.

39. Ye Y, Liu J, Xu J, Sun L, Chen M, Lan M. Nano-SiO2 induces apoptosis via activation of p53 and Bax mediated by oxidative stress in human hepatic cell line. Toxicol in Vitro. 2010;24(3):751-758.

40. Sayes CM, Marchione AA, Reed KL, Warheit DB. Comparative pulmonary toxicity assessments of $\mathrm{C} 60$ water suspensions in rats: few differences in fullerene toxicity in vivo in contrast to in vitro profiles. Nano Lett. 2007;7(8):2399-2406.

41. Roth S, Langguth P, Spicher K, Enzmann H. Comparative toxicity and cell-tissue distribution study on nanoparticular iron complexes using avian embryos and HepG2-cells. Transl Res. 2008;151(1):36-44. 


\section{Supplementary materials}
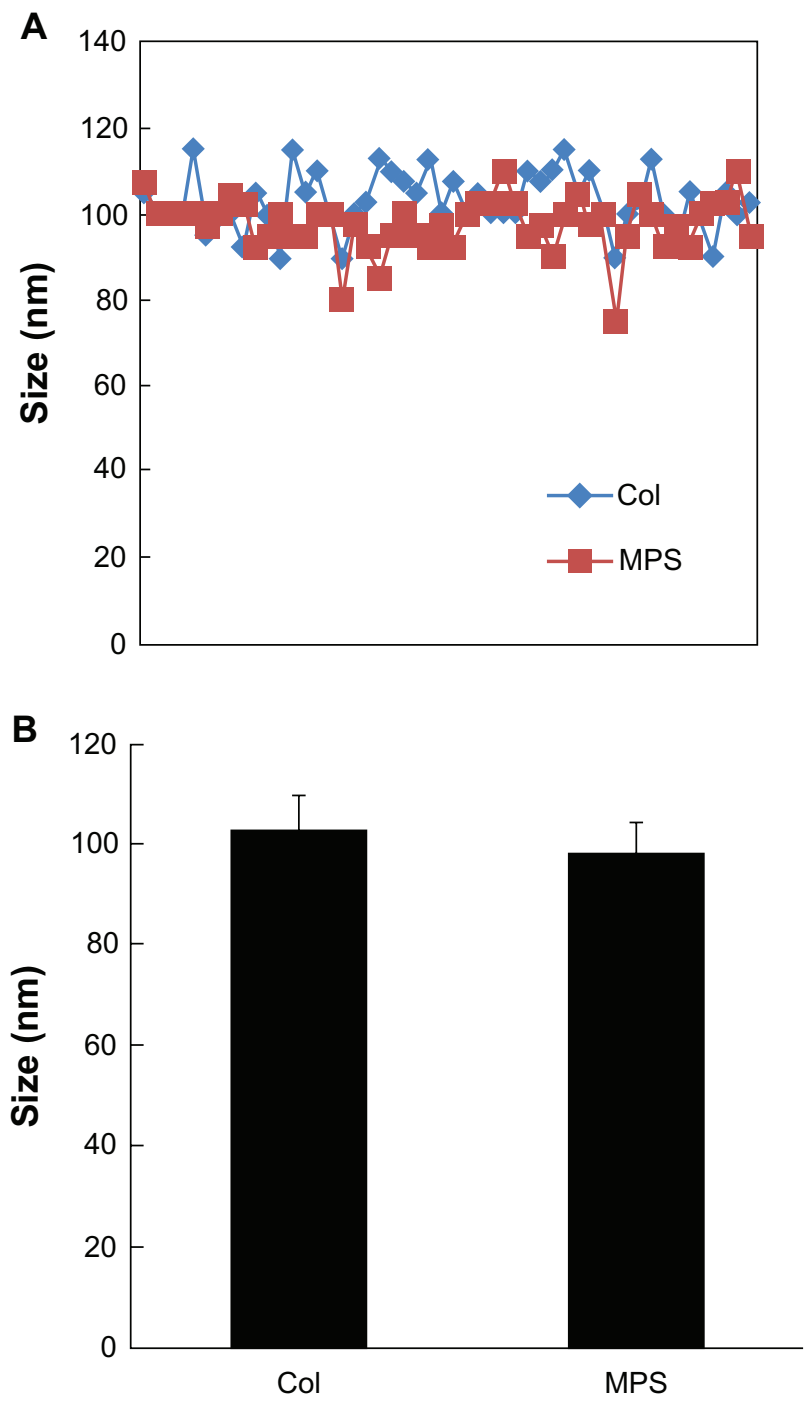

Figure SI Particle size distribution of MPS and Col NPs.

Abbreviations: MPS, mesoporous silica; Col, colloidal silica; NPs, nanoparticles.

Table SI Toxicity markers of liver and kidney in female BALB/c mice after intraperitoneal exposure to MPS and Col nanoparticles for 4 weeks

\begin{tabular}{lccc}
\hline Test substance & CON & $\begin{array}{l}\text { MPS 50 } \\
\text { (mg/kg/day) }\end{array}$ & $\begin{array}{l}\text { Col 50 } \\
\text { (mg/kg/day) }\end{array}$ \\
\hline AST (U/L) & $72.50 \pm 10.50$ & $75.50 \pm 0.50$ & $78.50 \pm 5.50$ \\
ALT (U/L) & $45.00 \pm 7.00$ & $44.00 \pm 0.00$ & $40.00 \pm 3.00$ \\
Creatinine (mg/dL) & $0.17 \pm 0.02$ & $0.15 \pm 0.02$ & $0.14 \pm 0.01$ \\
BUN (mg/dL) & $26.5 \pm 0.5$ & $30.5 \pm 3.5$ & $28.0 \pm 0.0$ \\
\hline
\end{tabular}

Notes: The results are shown as mean \pm SE $(n=5)$.

Abbreviations: CON, control; MPS, mesoporous silica; Col, colloidal silica; AST: aspartate aminotransferase activity; ALT, alanine aminotransferase activity; BUN, blood urea nitrogen; SE, standard error.
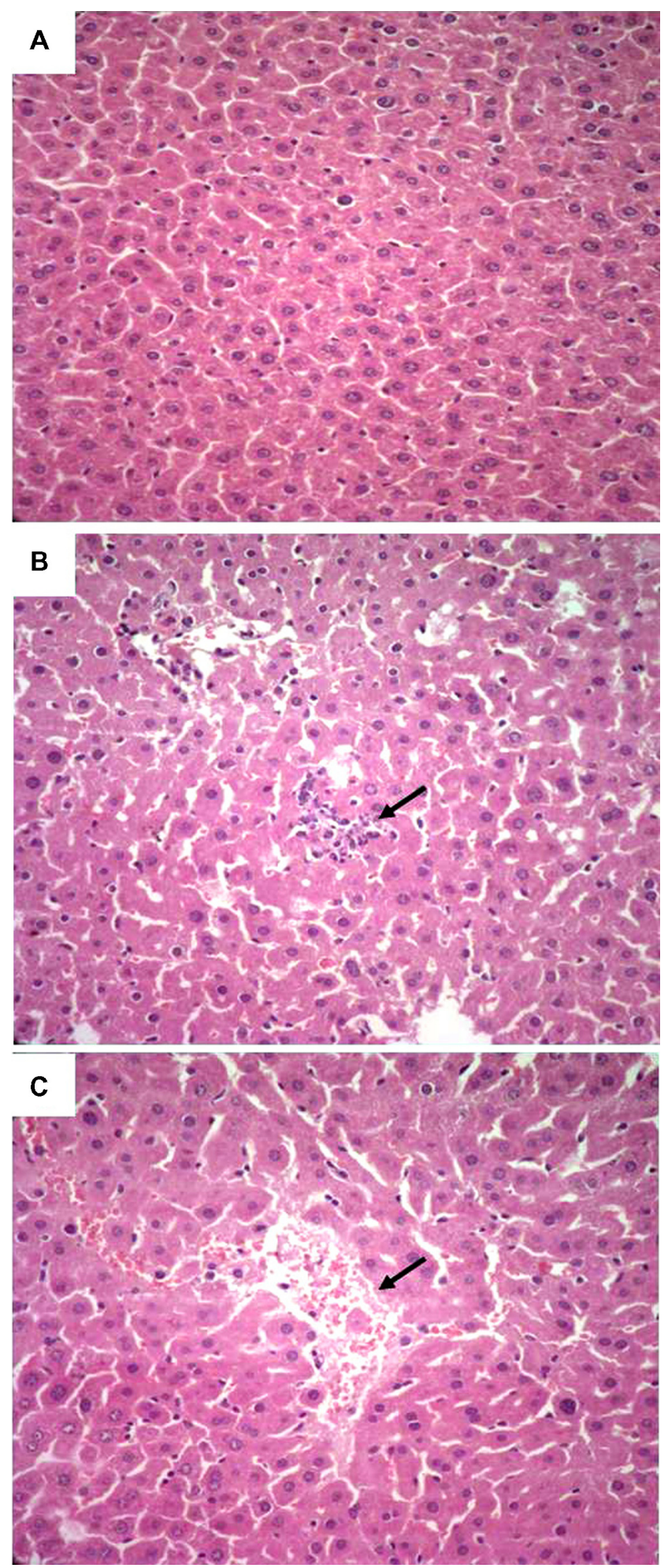

Figure S2 Histological analysis of the liver. Silica NPs were intraperitoneally administered to mice at a dose of $50 \mathrm{mg} / \mathrm{kg} /$ day. The histological section of the liver was stained with $\mathrm{H} \& \mathrm{E}$. (A) In the vehicle control, liver sections showed normal hepatic cells with well-preserved cytoplasm, prominent nucleus and nucleus. (B) The occasional spotty hepatic necrosis was observed in the liver tissue of both MPS- and Col-treated mice. (C) Focal sinusoidal dilatation with congestion was noted in the liver tissue of both MPS- and Col-treated mice. Note: Original magnification $\times 400$.

Abbreviations: NPs, nanoparticles; H\&E, hematoxylin and eosin. 
A

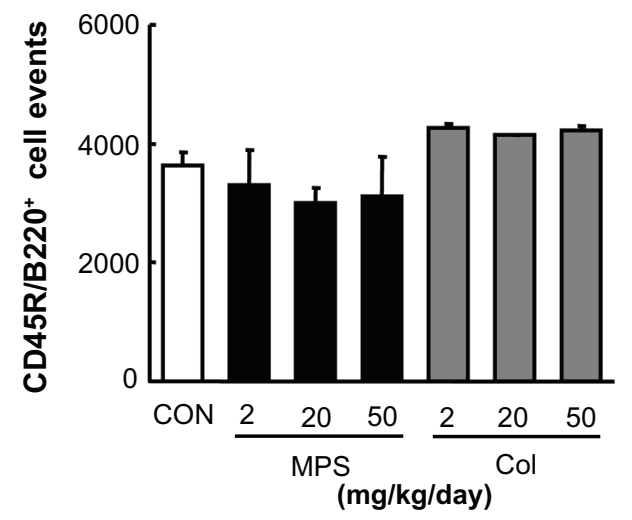

C

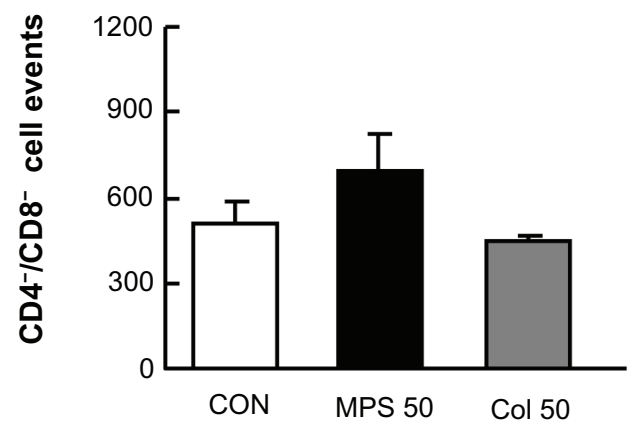

E

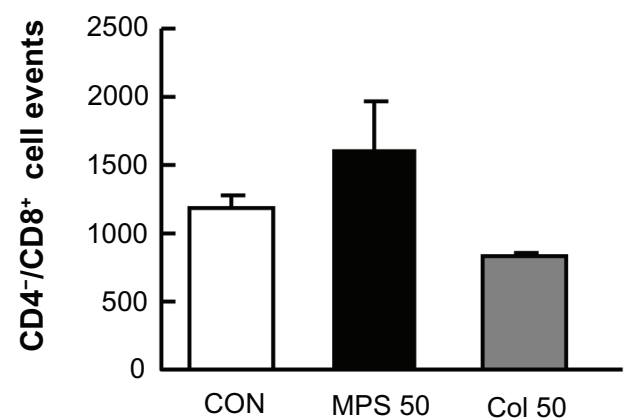

B
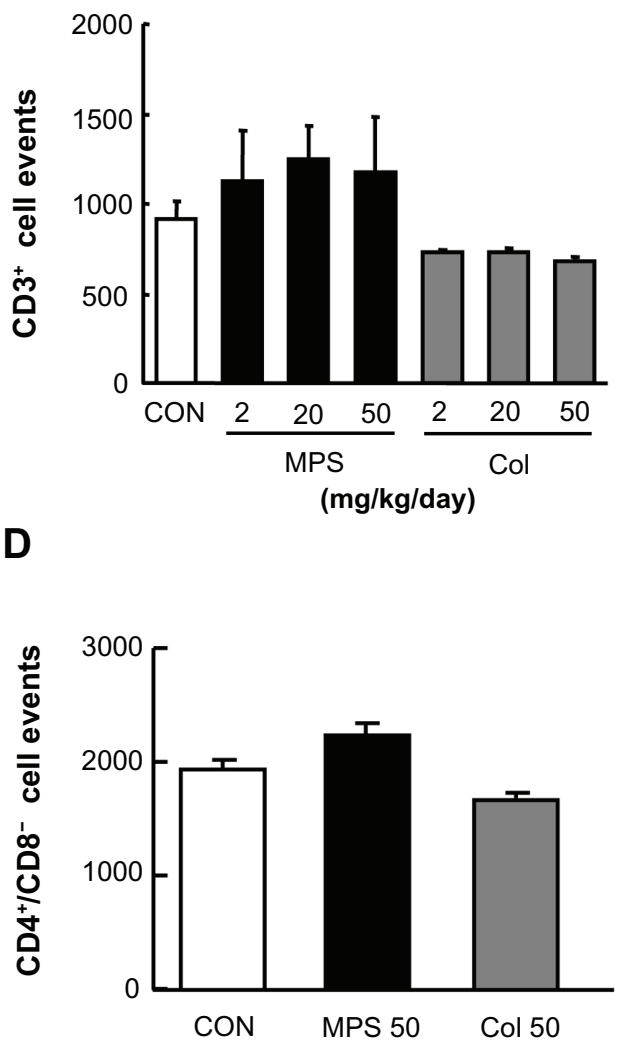

$\mathbf{F}$

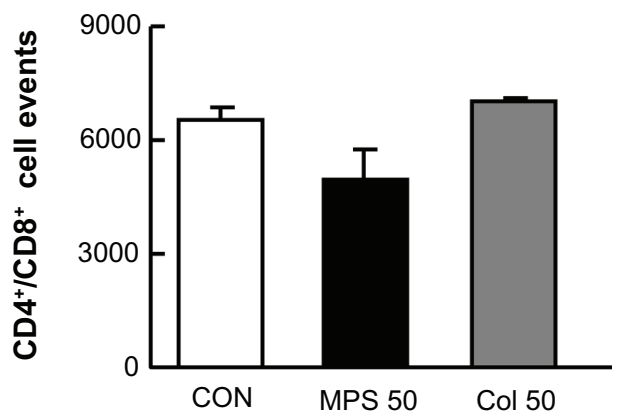

Figure S3 Effects of MPS and Col NPs on lymphocyte populations in the thymus. MPS and Col NPs were intraperitoneally administered to mice at a dose of 2, 20, or $50 \mathrm{mg} / \mathrm{kg} /$ day. Populations are shown as absolute cell counts for a given receptor. (A and B) Effects of MPS and Col NPs (50 mg/kg/day) on B- and T-lymphocyte populations, respectively. (C-F) Populations are shown as absolute cell counts for a given receptor.

Notes: The results are shown as mean \pm SE $(n=5)$.

Abbreviations: MPS, mesoporous silica; Col, colloidal silica; NPs, nanoparticles; CON, control; SE, standard error.

\section{Publish your work in this journal}

The International Journal of Nanomedicine is an international, peerreviewed journal focusing on the application of nanotechnology in diagnostics, therapeutics, and drug delivery systems throughout the biomedical field. This journal is indexed on PubMed Central,

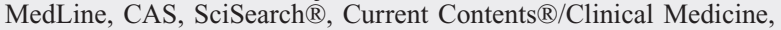

Journal Citation Reports/Science Edition, EMBase, Scopus and the Elsevier Bibliographic databases. The manuscript management system is completely online and includes a very quick and fair peer-review system, which is all easy to use. Visit http://www.dovepress.com/ testimonials.php to read real quotes from published authors. 